\title{
PENGARUH ELECTRONIC WORD OF MOUTH (EWOM), CELEBRITY ENDORSER, DAN ONLINE ADVERTISING TERHADAP BRAND AWARENESS
}

\author{
Anastasia Silvi Andrea \\ Program Studi Magister Manajemen Universitas Tarumanagara \\ anastasiasilvi95@gmail.com \\ Keni \\ Program Studi Magister Manajemen Universitas Tarumanagara \\ Masuk : 01-12-2020, revisi : 22-12-2020, diterima untuk diterbitkan : 22-12-2020
}

\begin{abstract}
This research is conducted to show the influence of electronic word of mouth (EWOM), celebrity endorsers, and online advertising on brand awareness. This descriptive research involved quantitative data collecting use a questionnaire as a data collection method. The researcher used the convenience sampling method to take 151 respondents with valid data. The data analysis technique used Partial Least Square - Structured Equation Modelling (PLSSEM) with the help of SmartPLS 3.3.2 software. This study concluded that 1) Electronic word of mouth has an insignificantly positive effect on brand awareness, 2) Celebrity endorser has a significantly positive effect on brand awareness, 3) Online advertising has a significant positive effect on brand awareness.
\end{abstract}

Keywords: Electronic Word of Mouth, Celebrity Endorser, Online Advertising, Brand Awareness

Abstrak: Penelitian ini dilakukan untuk menunjukkan pengaruh electronic word of mouth (EWOM), celebrity endorser, dan online advertising terhadap brand awareness. Penelitian deskriptif ini melibatkan pengumpulan data kuantitatif dengan menggunakan kuesioner secara cross-sectional sebagai metode pengumpulan data. Peneliti menggunakan metode convenience sampling untuk mengambil 151 responden dengan data yang valid. Teknik analisis data menggunakan Partial Least Square - Structured Equation Modelling (PLS-SEM) dengan bantuan software SmartPLS 3.3.2. Singkatnya, penelitian ini memperoleh kesimpulan bahwa 1) Electronic word of mouth berpengaruh positif tidak signifikan terhadap brand awareness, 2) Celebrity endorser berpengaruh positif signifikan terhadap brand awareness, 3) Online advertising berpengaruh positif signifikan terhadap brand awareness.

Kata Kunci: Electronic Word of Mouth, Celebrity Endorser, Online Advertising, Brand Awareness

\section{PENDAHULUAN}

Media sosial merupakan sarana informasi dan komunikasi yang sekarang ini sudah digunakan sebagai sarana kegiatan bisnis. Pada bulan April tahun 2020, terhitung ada sebanyak 64 juta pemilik akun Instagram di Indonesia (Statista Research Department, 2020). Hal ini tentu merupakan sebuah peluang bagi pebisnis untuk memperoleh keuntungan. Salah satu sektor bisnis yang paling banyak ditemui di Instagram adalah sektor kuliner khususnya jenis kue. Persaingan yang semakin ketat membuat para pebisnis kue online harus berusaha maksimal dalam menentukan strategi pemasaran yang tepat untuk menarik dan memperoleh pelanggan. Hal terpenting sebelumnya, pebisnis perlu menumbuhkan brand awareness yang merupakan bentuk kesadaran konsumen akan sebuah brand dari tahap mengenal hingga mampu mengingat kembali brand tersebut.

Syahvivar dan Ichlas (2018) menjelaskan bahwa electronic word of mouth akan mendorong perkenalan brand dari sebuah produk ke arah yang positif sehingga electronic word 
of mouth memiliki pengaruh yang positif terhadap brand awareness. Putri, Rachmawati, dan Prabowo (2016) menunjukkan electronic word of mouth memiliki pengaruh terhadap brand awareness.

Megawati (2017) melakukan penelitian dan menunjukkan bahwa celebrity endorser yang memiliki keahlian, prestasi, dan ketenaran di dunia hiburan akan membantu dalam pembentukan kesadaran konsumen. Sehingga celebrity endorser memiliki pengaruh terhadap brand awareness. Dalam penelitian Rahardian, Kusumawati, dan Irawan (2019), celebrity endorser memiliki pengaruh yang signifikan dan positif terhadap brand awareness.

Selain EWOM dan celebrity endorser, ada faktor lain yang mempengaruhi brand awareness. Menurut penelitian Arafaina dan Amri (2018), iklan online berpengaruh signifikan dan positif terhadap kesadaran merek (brand awareness). Penelitian Okolo, Okafor, dan Nduka (2018) juga menunjukkan online advertising berpengaruh positif terhadap brand awareness.

Berdasarkan latar belakang tersebut, tujuan dari penelitian ini adalah untuk menguji secara empiris pengaruh electronic word of mouth (EWOM), celebrity endorser, dan online advertising terhadap brand awareness. Hasil penelitian ini diharapkan dapat memberikan informasi kepada pelaku bisnis toko kue dan lainnya mengenai pentingnya meningkatkan brand awareness dalam tahap awal kegiatan bisnis online khususnya menggunakan strategi pemasaran yang tepat seperti EWOM, celebrity endorser, dan online advertising pada media sosial Instagram.

\section{TELAAH KEPUSTAKAAN \\ Electronic Word of Mouth}

Sulthana dan Vasantha (2019, p. 1) mengemukakan definisi dari electronic word of mouth adalah "sharing of information about product and services among people who interact with one another in virtual world of social media." Adapun Jalilvand dan Samiei (2012, p. 1) mengungkapkan "with the advancement of Internet technologies, increasing numbers of consumers are using the Internet to seek information about a product or a company, and eWOM has emerged as a result." Dapat disimpulkan bahwa electronic word of mouth adalah bentuk komunikasi antar konsumen yang menginformasikan sebuah produk atau pelayanan penjual melalui teknologi digital berbasis internet seperti salah satunya media sosial.

\section{Celebrity Endorser}

McCracken (1989, p. 310) mendefinisikan celebrity endorser sebagai berikut "any individual who enjoys public recognition and who uses this recognition on behalf of a consumer good by appearing with it in an advertisement." Kemudian Setiawan dan Rabuani (2019, p. 5) mendeskripsikan celebrity endorser sebagai "orang-orang yang menyampaikan pesan pada suatu iklan." Berdasarkan definisi yang ada dapat disimpulkan celebrity endorser adalah seorang individu yang dikenal dan disenangi masyarakat luas yang digunakan oleh suatu perusahaan tertentu untuk menyampaikan pesan iklan dan memasarkan suatu produk.

\section{Online Advertising}

Anbumalar et al., (2019, p. 577) mendefinisikan online advertising sebagai "a form of marketing which uses the online platforms to promote the products. It helps businesses in targeting global customers." Selanjutnya Rajalakshmi dan Rani (2017, p. 28) mendefinisikan online advertising sebagai "a type of mass communication which is based on traditional form of advertising but develops its own communication strategies in correlation with the new technical and medium based requirements. Broadly, online advertising is about delivering advertisements to Internet or online users via web sites, e-mail, ad-supported software and internet-enabled smart phones." Kesimpulannya online advertising adalah bentuk penyampaian pesan pemasaran produk maupun jasa melalui berbagai platform online yang diakses dengan internet dengan tujuan untuk menarik pelanggan. 


\section{Brand Awareness}

Ugwuanyi, Okeke, dan Emezue (2018, p. 17) mendefinisikan brand awareness sebagai "a veritable tool for firms to achieve competitive advantage as it will help consumers recall the brand given a product category" Sementara Chandra dan Keni (2019, p. 178) mendefinisikan brand awareness sebagai "kemampuan konsumen untuk mengenali dan mengingat kembali sebuah merek dengan cukup rinci untuk melakukan pembelian." Dapat disimpulkan brand awareness adalah bentuk kesadaran konsumen akan sebuah brand dari tahap mengenal sebuah brand hingga mampu mengingat kembali brand tersebut.

\section{Kaitan antar Variabel}

\section{Kaitan antara Electronic Word of Mouth dan Brand Awareness}

Penelitian yang dilakukan oleh Syahvivar dan Ichlas (2018) menjelaskan bahwa electronic word of mouth akan mendorong perkenalan brand dari sebuah produk ke arah yang positif sehingga electronic word of mouth memiliki pengaruh yang positif terhadap brand awareness. Hal serupa juga diungkapkan oleh Putri, Rachmawati, dan Prabowo (2016) menunjukkan electronic word of mouth memiliki pengaruh terhadap brand awareness. Berdasarkan uraian tersebut, hipotesis penelitian $\left(\mathrm{H}_{1}\right)$ adalah:

$\mathrm{H}_{1}$ : Electronic Word of Mouth memiliki pengaruh positif terhadap Brand Awareness

\section{Kaitan antara Celebrity Endorser dan Brand Awareness}

Dalam penelitian Megawati (2017), ditunjukkan bahwa celebrity endorser yang memiliki keahlian, prestasi, dan ketenaran di dunia hiburan akan membantu dalam pembentukkan kesadaran konsumen. Sehingga celebrity endorser memiliki pengaruh terhadap brand awareness. Dalam penelitian Rahardian, Kusumawati, dan Irawan (2019), celebrity endorser memiliki pengaruh yang signifikan dan positif terhadap brand awareness. Berdasarkan uraian tersebut, hipotesis penelitian $\left(\mathrm{H}_{2}\right)$ adalah:

$\mathrm{H}_{2}$ : Celebrity Endorser memiliki pengaruh postif terhadap Brand Awareness

\section{Kaitan antara Online Advertising dan Brand Awareness}

Penelitian Arafaina dan Amri (2018) menunjukkan iklan online berpengaruh signifikan dan positif terhadap kesadaran merek (brand awareness). Hal serupa disampaikan pada penelitian Okolo, Okafor, dan Nduka (2018) bahwa online advertising berpengaruh positif terhadap brand awareness. Berdasarkan uraian tersebut, hipotesis penelitian $\left(\mathrm{H}_{3}\right)$ adalah: $\mathrm{H}_{3}$ : Online Advertising memiliki pengaruh positif terhadap Brand Awareness

\section{METODOLOGI PENELITIAN}

\section{Populasi dan Metode Pengambilan Sampel}

Penelitian deskriptif ini melakukan pengumpulan data secara cross-sectional dengan sumber data primer. Metode pengambilan sampel menggunakan non-probability sampling secara convenience sampling terhadap sebanyak 151 responden pengguna Instagram. Berdasarkan data yang terkumpul, responden yang didapati mayoritas berada dalam golongan umur 17-25 tahun yaitu sebesar 84,8\% dan mayoritas merupakan karyawan, yakni sebesar $64,2 \%$.

\section{Variabel dan Pengukuran}

Dalam penelitian ini, terdapat 3 buah variabel bebas (electronic word of mouth (EWOM), celebrity endorser, dan online advertising) dan 1 variabel tidak bebas (brand awareness). Untuk mengukur validitas dan reliabilitas dari variabel ini, digunakan beberapa instrument yang di adaptasi dari studi penelitian terdahulu. Berikut ini adalah tabel yang menunjukan pengukuran setiap variabel dan sumber yang dipilih: 
Tabel 1

Variabel dan Pengukuran

\begin{tabular}{|c|c|c|}
\hline Variabel & Item & Sumber \\
\hline \multicolumn{3}{|c|}{ Variabel Independent } \\
\hline Electronic Word of Mouth & 5 & Jalilvand \& Samiei (2012) \\
\hline Celebrity Endorser & 10 & Megawati (2017); Setiawan \& Rabuani (2019) \\
\hline Online Advertising & 6 & Putri, Rachmawati, \& Prabowo (2016) \\
\hline \multicolumn{3}{|c|}{ Variabel Dependent } \\
\hline Brand Awareness & 6 & $\begin{array}{c}\text { Putri, Rachmawati, \& Prabowo (2016) } \\
\text { Setiawan \& Rabuani (2019) }\end{array}$ \\
\hline
\end{tabular}

\section{Metode Analisis Data}

Data yang diperoleh kemudian dianalisis menggunakan Partial Least Square Structured Equation Modelling (PLS-SEM) dengan bantuan software SmartPLS 3.3.2. Analisis data ini dilakukan dengan tiga tahap, yaitu analisis outer model, analisis inner model, dan pengujian hipotesis.

\section{HASIL PENELITIAN DAN PEMBAHASAN}

Dalam menguji validitas dilakukan uji Average Variance Extracted (AVE). Nilai AVE dari masing-masing variabel dalam penelitian ini memenuhi syarat validitas dikarenakan nilai AVE yang dihasilkan > 0,5. Selanjutnya dilakukan uji reliabilitas dengan melihat nilai Cronbach's Alpha dan Composite Reliability, yang mana dalam penelitian ini masing-masing variabel diperoleh angka > 0,7 sehingga dapat dikatakan instrumen penelitian yang digunakan memenuhi syarat reliabilitas.

Selanjutnya, berikut ini adalah tabel yang menunjukkan hasil pengujian hipotesis penelitian ini:

\section{Tabel 2}

Hasil Pengujian Hipotesis

\begin{tabular}{|c|c|c|c|c|}
\hline & Path Coefficient & t-statistics & p-value & Keterangan \\
\hline Electronic Word of Mouth $(\mathrm{EWOM}) \rightarrow$ Brand Awareness & 0,061 & 0,786 & 0,432 & Ditolak \\
\hline Celebrity Endorser $\rightarrow$ Brand Awareness & 0,302 & 3,174 & 0,002 & Tidak Ditolak \\
\hline Online Advertising $\rightarrow$ Brand Awareness & 0,451 & 4,424 & 0,000 & Tidak Ditolak \\
\hline
\end{tabular}

Pada hasil Path Coefficient menunjukkan hubungan antar variabel electronic word of mouth, celebrity endorser, dan online advertising memiliki kontribusi terhadap brand awareness ke arah yang positif. Selanjutnya pengujian hipotesis dilakukan dengan uji-t dan uji signifikansi yang dapat terlihat pada tabel 2. Berdasarkan hasil pengujian hipotesis, maka dapat disimpulkan hipotesis $\mathrm{H}_{1}$ ini tidak sesuai dengan penelitian yang dilakukan Syahvivar dan Ichlas (2018) yang menunjukkan electronic word of mouth dapat meningkatkan brand awareness. Penelitian ini juga tidak sejalan dengan penelitian Putri, Rachmawati, dan Prabowo (2016) yang menunjukkan semakin banyak pelanggan mengulas, menjelaskan, dan menginformasikan tentang produk dari sebuah brand maka mampu membantu seseorang untuk mengenal dan mengingat brand tersebut. Perbedaan yang dihasilkan dalam penelitian ini dikarenakan dalam menciptakan brand awareness, masyarakat lebih terkesan dengan desain dan penataan halaman sebuah akun Instagram toko kue dibandingkan dengan ulasan konsumen. Ulasan-ulasan yang ada memang membawa konsumen untuk melihat halaman Instagram toko kue, kemudian desain tampilan Instagram toko kue, bentuk kue, foto-foto dan promosi yang menarik, merupakan hal-hal yang membuat masyarakat terkesan dan menyukai toko kue.

Hasil Pengujian hipotesis kedua menunjukkan bahwa celebrity endorser berpengaruh signifikan positif terhadap brand awareness, sehingga dapat disimpulkan hipotesis $\mathrm{H}_{2}$ tidak ditolak. Hasil penelitian ini sejalan dengan penelitian yang dilakukan oleh Megawati (2017) yang meneliti pengaruh celebrity endorser terhadap keputusan pembelian melalui variabel mediasi brand awareness juga menjelaskan bahwa celebrity endorser berpengaruh terhadap keputusan pembelian melalui brand awareness. Adapun penelitian lain dari Rahardian, 
Kusumawati, dan Irawan (2019) juga mendapatkan hasil penelitian bahwa celebrity endorser memiliki pengaruh yang signifikan dan positif terhadap brand awareness, dimana semakin positif celebrity endorser maka semakin meningkatkan brand awareness. Celebrity endorser yang dipilih merupakan selebriti terkenal yang berpengalaman, berpenampilan menarik dan juga memiliki paras yang mendukung iklan toko kue tersebut, sehingga apa yang disampaikan oleh selebriti tersebut juga dapat dipercaya oleh masyarakat.

Hasil pengujian hipotesis yang terakhir menunjukkan bahwa online advertising berpengaruh signifikan positif terhadap brand awareness. Hasil ini sejalan dengan penelitian yang dilakukan oleh Arafaina dan Amri (2018) menunjukkan iklan online berpengaruh signifikan dan positif terhadap kesadaran merek (brand awareness). Penelitian ini juga sejalan dengan penelitian yang dilakukan oleh Okolo, Okafor, dan Nduka (2018) bahwa online advertising berpengaruh positif terhadap brand awareness. Penelitian ini memperoleh hasil yang menunjukkan bahwa tampilan gambar yang baik dan menarik dari sebuah iklan online disukai oleh masyarakat. Masyarakat dapat tertarik dengan informasi yang mudah dimengerti, dan promosi-promosi menarik yang ditunjukkan iklan online. Dengan ini, kesadaran masyarakat terbentuk akan adanya sebuah brand sehingga masyarakat mampu mengenal dan mengingat merek tersebut melalui iklan online.

\section{KESIMPULAN DAN SARAN}

Hasil penelitian ini menunjukkan bahwa pertama variabel electronic word of mouth (EWOM) berpengaruh secara positif namun tidak signifikan terhadap brand awareness. Hasil penelitian yang kedua menunjukkan variabel celebrity endorser berpengaruh positif dan signifikan terhadap brand awareness. Hasil penelitian yang terakhir, online advertising juga berpengaruh positif dan signifikan terhadap brand awareness.

\section{IMPLIKASI MANAJERIAL}

Dari hasil tersebut peneliti memberikan saran agar perusahaan dapat lebih berfokus terhadap faktor celebrity awareness dan online advertising. Perusahaan disarankan untuk memilih selebriti yang memiliki ketenaran lebih luas serta pengetahuan dan kemampuan dalam mempengaruhi dan meyakinkan masyarakat di segala lapisan agar dapat dipercaya sehingga terbangunnya keberadaan merek dan citra perusahaan.

Selanjutnya perusahaan juga disarankan untuk selalu menampilkan online advertising secara rutin dengan informasi yang dibutuhkan konsumen dan informasi manfaat produk seperti dapat dijadikan kue ulang tahun, kue perayaan hari anniversary, kelulusan dan hari-hari istimewa lainnya. Selain itu perusahaan harus dapat mempertahankan format periklanan yang lengkap dan mudah dimengerti oleh seluruh lapisan masyarakat baik dari segi bahasa, gambar dan sesuai dengan tren yang ada.

Hal ini bukan berarti perusahaan melupakan faktor electronic word of mouth untuk meningkatkan brand awareness, sebaliknya perusahaan harus tetap mempertahankan pelayanan yang terbaik untuk mendapatkan banyak ulasan dari para konsumen, karena electronic word of mouth akan mengundang masyarakat menuju ke Instagram perusahaan.

\section{DAFTAR PUSTAKA}

Anbumalar, S., Vignesh, C., Dharani, V. S., \& Abarna, M. (2019). Effectiveness of online advertising in India. International Journal of Innovative Technology and Exploring Engineering, 8(12S), 577-579. https://doi.org/10.35940/ijitee.11142.10812s19

Arafaina, Y., \& Amri, A. (2018). Pengaruh iklan online Zalora Indonesia terhadap kesadaran merek pada masyarakat Kota Banda Aceh. Jurnal Ilmiah Mahasiswa FISIP Unsyiah, 3(2), 233-244. 
Chandra, C., \& Keni, K. (2019). Pengaruh brand awareness, brand association, perceived quality, dan brand loyalty terhadap customer purchase decision. Jurnal Muara Ilmu Ekonomi Dan Bisnis, 3(1), 176-185. https://doi.org/10.24912/jmieb.v3i1.3506

Jalilvand, M. R., \& Samiei, N. (2012). The effect of electronic word of mouth on brand image and purchase intention An empirical study in the automobile industry in Iran. Marketing Intelligence \& Planning, 30(4), 460-476. https://doi.org/10.1108/02634501211231946

McCracken, G. (1989). Who is the celebrity endorser? Cultural foundations of the endorsement process. Journal of Consumer Research, 16(3), 310-321. https://doi.org/10.1086/209217

Megawati, P. (2017). Pengaruh celebrity endorser, word of mouth, dan tagline terhadap keputusan pembelian melalui brand awareness. In Skripsi. Universitas Sanata Dharma.

Okolo, V. O., Okafor, J. N., Obikeze, C. O., \& Nduka, C. (2018). Influence of online advertising on consumer brand awareness and patronage of financial institutions in Enugu: A study of United Bank for Africa (UBA). Global Scientific Journal, 6(8), 452456.

Putri, N., Rachmawati, I., \& Prabowo, F. S. A. (2016). Pengaruh electronic word of mouth terhadap brand equity Indomie (Studi pada followers official account jejaring sosial Indomie). E-Proceeding of Management, 3(3), 2976-2984. https://openlibrarypublications.telkomuniversity.ac.id/index.php/management/article/vie w/2984/2830

Rahardian, M. D., Kusumawati, A., \& Irawan, A. (2019). Pengaruh tagline iklan dan celebrity endorser terhadap brand awareness dan minat beli (Survei pada mahasiswa program sarjana pengguna smartphone Oppo F3 Plus di Universitas Brawijaya). Jurnal Administrasi Bisnis, 75(1), 10-18.

Rajalakshmi, C., \& Rani, P. U. (2017). Types of online advertisements and online buyers. Management Global Review, November, 28-35. https://www.researchgate.net/publication/320909214_Types_of_Online_Advertisements _and_Online_Buyers

Setiawan, B., \& Rabuani, C. C. (2019). Pengaruh iklan dan endorser terhadap brand awareness serta dampaknya pada keputusan pembelian. Jurnal Aplikasi Ekonomi, Akuntansi Dan Bisnis, 1(1), 51-65. https://doi.org/10.35212/277621

Statista Research Department. (2020). Leading countries based on Instagram audience size as of October 2020. https://www.statista.com/statistics/578364/countries-with-mostinstagram-users/

Sulthana, A. N., \& Vasantha, S. (2019). Influence of electronic word of mouth eWOM on purchase intention. International Journal of Scientific and Technology Research, 8(10), $1-5$.

Syahrivar, J., \& Ichlas, A. M. (2018). The impact of electronic word of mouth (E-WoM) on brand equity of imported shoes: Does a good online brand equity result in high customers' involvements in purchasing decisions? The Asian Journal of Technology Management (AJTM), 11(1), 57-69. https://doi.org/10.12695/ajtm.2018.11.1.5

Ugwuanyi, C. C., Okeke, C. V., \& Emezue, L. N. (2018). Celebrity advertising, brand awareness and brand recognition: A structural equation modelling approach. European Journal of Business and Management, 10(28), 17-24. https://iiste.org/Journals/index.php/EJBM/article/view/44533 